\title{
LXXVI. On the mathematical form of the Gothic pendent
}

\author{
James D. Forbes Esq. F.R.S. L.\& E.
}

To cite this article: James D. Forbes Esq. F.R.S. L.\& E. (1836) LXXVI. On the mathematical form of the Gothic pendent, Philosophical Magazine Series 3, 8:49, 449-455, DOI: 10.1080/14786443608648918

To link to this article: http://dx.doi.org/10.1080/14786443608648918

册 Published online: 01 Jun 2009.

Submit your article to this journal $₫$

Џ Article views: 2

Q View related articles $₫$ 
LONDON AND EDINBURGH

\title{
PHILOSOPHICAL MAGAZINE
}

\author{
AN D \\ JOURNAL OF SCIENCE. \\ [THIRD SERIES.] \\ $J U N E 1836$.
}

LXXVI. On the Mathematical Form of the Gothic Pendent. By James D. Forbes, Esq., F.R.S.L.\&.E., Professor of Natural Philosophy in the University of Edinburgh.*

[With a Plate.]

THERE are few points in the history of science more curious than the display of theoretical skill afforded by the masonic works of the darker ages. Wherever the Gothic architects derived their knowledge, it must have been both extensive and sound; and now that the stigma attached to the unfortunate appellation of Gothic has in a great measure passed away, and it is admitted that pure taste may be shown in following other than the Grecian models, we may be permitted to gather lessons from these remoter times, tending to show that the basis, at least, of what is pleasing in architecture is not of a capricious or ephemeral character, but reposes upon the immutable substratum of natural laws.

When we select the best works which have characterized the middle ages, including both the Norman and the pointed styles, - but especially the latter, from its earliest introduction into Italy during the Imperial decline down to the sixteenth century, -we are sometimes at a loss to say whether the sound mechanical principles employed in such structures have been more happily displayed or artfully concealed. To con-

* Read before the Royal Society of Edinburgh, Feb. 1, 1836 ; and communicated by the Author.

Third Series. Vol. 8. No. 49. June 1836. 
fine ourselves to the Pointed style, we have a beautiful accordance amongst the perpetually rising lines of a symmetrical structure. These carry the eye from the base to the summit of a building with a consciousness that such a general disposition of parts is conformable to the particular disposition of details; we have a superposition of less solid upon more condensed parts, retreating buttresses and tapered pinnacles. Then the peculiar form of the pointed arch, which, whilst it leads the eye upwards, has that in it which convinces us of its fitness to be loaded at the summit, and to bear in stately equipoise those spires or towers, which had their especial adaptation to the objects of the sacred edifices with which they were connected. The mutual support afforded by the parts was not only always adequate, but (in the best models) amply enough developed to prove to the eye that it was so. Pillars are placed where they might have been dispensed with, but they are never placed where the eye sees at once their inutility. Spandrels of arches are lightened, though the voussoirs might have sustained the load; open canopies with loaded vertices, though their lightness strikes the eye with a pleasing astonishment, are never suffered to inspire us with a dread of instability.

Yet it often happens that the real sources of security in Gothic architecture have been as carefully kept out of sight, as that amount of protection required by the eye was secured*. We are perfectly capable of admiring the interior of a groined stone roof, without concerning ourselves much with the mode in which the lateral thrust is opposed. The vertical weight is that which chiefly affects our senses, and that the walls should appear, as well as be, strong enough to sustain it. Yet every carpenter knows that the lateral thrust of his roof must somehow or other be resisted. Much more so when stone is used, and arches which render the employment of tie-beams impracticable. The Gothic architects from a very early period transferred the pressure to individual points of the vertical walls, (for instance, by the beautiful conoicial groining of King's College Chapel, Cambridge,) and sustained the pressures by flying buttresses of the most elegant forms, which conveyed the thrust to the lateral solid buttresses, surmounted by those elegant but ponderous pinnacles, which whilst they appear to be placed but for ornament, are in reality preventing the displacement of these stays, and thus

* I find that Mr. Willis, in his interesting and elegant work on Italian Gothic Architecture, has expressed himself in almost the same terms that I have here used. 
conducing to the great end in view. The supports of the towers and spires of churches are in many cases quite different from those which the eye of the spectator is taught to consider as the real sources of stability.

We might say truly of the Gothic architects, "Ars est celare artem"; but we have at present rather to do with the cases in which it is displayed. Though we are very far from thinking that the principles of taste are in all cases referrible to principles of reasoning, we believe that in a vast majority of cases they are so, and frequently to mechanical principles by no means obvious. The tact, -as distinguished from definite knowledge, - which experience conveys, is one of the most curious of our faculties, and we are often astonished on discovering upon what remote analogies or reasoning our homeliest conclusions are founded. That there is a point beyond which mere logic is unavailable, and where its application would be absurd, few will deny: but we must commence with the clear conception of a design to be answered, and means conspiring to the given end; nor must our superstructure be inconsistent with that design, nor opposed to, if it does not conspire with, those means. The more obvious conditions of stability must be fulfilled; and any ornament interfering with them is not only superfluous but displeasing. Every conspicuous part must have its apparent use: no portion must have a greater share of duty assigned to it than it appears, as well as is, able to sustain. Some of the architects of the middle ages delighted in constructing paradoxes in stone. They violated the rules of good taste, because they violated the rules of common sense. Every one sees that helical pillars, if they be what they appear to be, are incapable of bearing a heavy load. Short dumpy pillars seem disproportioned to the chance of their flexure; very slender ones, unless most skilfully grouped, look as if a touch of the finger would bend them at the middle of their length. Orders of architecture of increasing heaviness as we ascend, stone staircases which seem hung in air, and leaning towers (if we could conceive that it ever occurred to an architect to execute such a monstrosity), would be equal violations of the canons of taste and reason. On the other hand, the most moderately experienced eye cannot look at a well-balanced building, whatever may be its order of architecture, or at a well-trussed roof, however simple its materials, without a degree of: conscious satisfaction, of the cause of which we are for a moment ignorant. Though we do not pretend that the eye can detect by mere general experience the concordance between parts which the more refined mechanical problems present, 
such as the relation between the intrados and extrados of an arch, or the form of an equilibrated dome, yet it so happens that our consciousness of fitness and the accuracy of our theoretical views desert us nearly at the same moment, and that we are obliged to have recourse to that middle path which practical sagacity, long experience, and sound mechanical views point out.

Professor Robison, in one of those admirable articles on applied science with which he enriched the Encyclopadia Britannica, and which remarkably exhibit the characteristics just mentioned, after an eloquent appeal on behalf of the dignity of roofs, has the following pertinent remarks.

"The Gothic architecture is, perhaps, entitled to the name of Rational Architecture, and its beauty is founded on the characteristic distinction of our species. It deserves cultivation: not the pitiful, servile and unskilled copying of the monuments; this will produce incongruities and absurdities equal to any that have crept into the Greek architecture: but let us examine with attention the nice disposition of the groins end spandrels; let us study the tracery and knots, not as ornaments, but as useful members; let us observe how they have made their walls like honeycombs, and admire their ingenuity as we pretend to admire the instinct infused by the great Architect into the bee*."

Having had occasion to consider some time ago what should be the form of a depending column of uniform material, such that the area of section should always be proportional to the weight sustained, I was led by an easy analysis to conclude, that it must be the solid generated by the revolution of the logarithmic curve round its axis. The mere imagination of such a depending body reminded me of the beautiful pendents of Gothic architecture, which, though we more frequently see them on a small than a large scale, have always

“ The Greeks were enabled to execute their colossal buildings only by using immense blocks of the hardest materials. The Norman mason could raise a building to the skies without using $a$ stone which a labourer could not carry to the top on his back. Their architects studied the principles of equilibrium; and having attained a wonderful knowledge of it, they indulged themselves in exhibiting remarkable instances. We call this false taste, and say that the appearance of insecurity is the greatest fault. But this is owing to our habits: our thoughts may be said to run in a wooden train, and certain simple maxims of carpentry are familiar to our imagination; and in the careful adherence to these consists the beauty and symmetry of the Greek architecture. Had we been as much habituated to the equilibrium of pressure, this apparent insecurity would not have met our eye: we would have perceived the strength, and we should have relished the ingenuity."-Art. Roop, Encyclop. Britann:, Third Edit., vol, xvi. p. $463 ; 10,9$. 
conveyed to my mind a sense of peculiar elegance; and this notwithstanding that they occur only in the later periods of Gothic architecture, and are rather contemptuously passed over by the connoisseur as merely exaggerated bosses.

I have not been able to discover either in practical or descriptive works any indication of the real figure of Gothic pendents. I am perfectly satisfied, however, that if they are not logarithmic spindles, they ought to be so. The gradual modification of the curve from the long finely tapered extremity to the point of greatest curvature, and then the flat receding branch, corresponds to a multitude of Gothic details; and an exact sketch from the best models I have been able to procure has led me to the same conclusion.

It is not to be supposed that the architects could have had a curve in view which was not known until long after the termination of the real Gothic æra; I conceive that it was merely a rude approximation to that figure which might satisfy the eye by exhibiting some parity between the area of the cohering surfaces and the mass to be sustained. When we come to reflect upon extreme cases, this supposition of the judgement exercised by the eye will not appear extravagant. A depending cylinder seems heavy at its lower part, because the area of section is disproportioned to the weight it has to sustain, and hence the upper part will appear weak and contracted; for, if the depending mass be loaded until the limits of cohesion are passed, rupture must take place there. Any body materially increasing inferiorly would be still more displeasing. A uniform cone with the apex downwards will, I believe, strike every one as overloaded near its centre, and every figure having its concavity directed towards its axis would be still more disagreeable. The form, therefore, must be concave outwardly, and we may easily imagine how the abstraction of matter from the middle of the depending cone, and the transfer of it towards its upper and lower extremities, might produce a curve similar to the logarithmic. This figure, in fact, embraces the essential part of what Professor Robison calls rational architecture, - sufficiency without redundancy: the section on which strength depends increases in proportion to the mass to be sustained.

We may observe also that since the lower extremity should be indefinitely extended (the curve becoming asymptotic,) the eye could not be satisfied by an abrupt termination; there is consequently always an inferior expansion which may seem to replace the asymptotic part of the spindle removed, and without which the termination might appear abrupt.

One characteristic of the Gothic architecture is unity of de- 
sign. We accordingly find the peculiar figure of the pendent carried into the minuter depending ornaments for the sake of symmetry; though the scale is almost too small to require the curve of equal strength to satisfy the eye. It is quite obvious too, that to reverse the case we have described, and to make masses of the form of pendents resting on their smaller bases to sustain weights, is equally repugnant to the principles of good architecture and good sense.

In all cases the strength actually given to pendents enormously exceeds that requisite for their cohesion. It appears from the following simple analysis that the modulus or subtangent of the logarithmic curve, must, in order exactly to prevent rupture, be equal to twice the modulus of cohesion of the substance in feet.

" Required the figure of a depending body which shall be just within the limit of cohesion at every part of its length." Let $s^{2}$ represent the area of its section corresponding to any point $x$ in a given vertical ascending line. Since the condition infers that the increase of section shall be in a constant ratio to the increased volume of the solid,

$$
a d \cdot s^{2}=s^{2} d x
$$

( $a$ being a constant); and integrating

$$
x=a \cdot \text { hyp. } \log s^{2}+c .
$$

If we assume the body to be a solid of revolution, and likewise that the variable radius $r$ shall become equal to unity when $x=0$, we shall have for the corrected integral

$$
x=2 a \text {. hyp. } \log r \text {. }
$$

Hence the contour of the pendent will be a logarithmic curve, whose subtangent $=2 a$.

Now, since it is required that the increment of cohering surface shall be just capable of supporting the increment of mass, we must have the quantity $\frac{s^{2} d x}{d \cdot s^{2}}$, or $a$, equal to the modulus of cohesion of the substance employed expressed in linear measure. Consequently the subtangent is equal to twice the modulus of cohesion, and for a self-supported body of uniform thickness, the measure of the one and the other would be the same.

In the cases of white marble and Portland stone the moduli of cohesion have been stated at 1542 and 945 feet respectively. The subtangents would, therefore, be 3084 and 1890 feet. We may thence calculate the logarithm of 2 upon those scales, or the vertical height in which the radius of the section doubles itself. This will be found to be 2138 feet in the case 
of white marble, and 1310 feet in that of Portland stone*. In a pendent $n$ times the necessary strength $r$ will be doubled in the $n$th part of the above intervals.

\section{Explanation of Plate IV.}

Fig. 1. Gothic Pendent.

Fig. 2. Pendents of Uniform Strength : $a$, of Portland Stone; $b$, of White Marble.

Edinburgh, January 16, 1836.

LXXVII. Experimental and Physical Researches in Electricity and Magnetism. By the Rev. Wildiam Ritchie, LL.D., F.R.S., Professor of Natural Philosophy in the Royal Institution and in the University of London. $\uparrow$

1 A soon as the magneto-electric spark and shock were A obtained, it must have been observed that the size of the spark increased with the length of the coil employed, and afterwards diminished till it at length disappeared. The physiological effects are also exceedingly feeble with a short coil, and continue to increase by increasing the length of the wire long after the spark has attained its maximum brightness. In experimental research, and particularly in public lectures, it is very convenient to obtain both effects from the same magnet and revolving lifter. This is easily and expeditiously accomplished by the following arrangement, which will be understood by simply inspecting the annexed figure.

$\mathrm{A} \mathrm{B}$ is the hollow axis, $\mathrm{CD}$ the solid axis passing through the former, metallic contact being prevented by a cylinder of wood. B is the disc of copper or platina dipping into the mercury contained in the cell $F$, and $G$ the star or point dipping into the cell H. Two copper wires having their ends formed into a close spiral by rolling them round a thick wire are soldered to the hollow and solid axis at

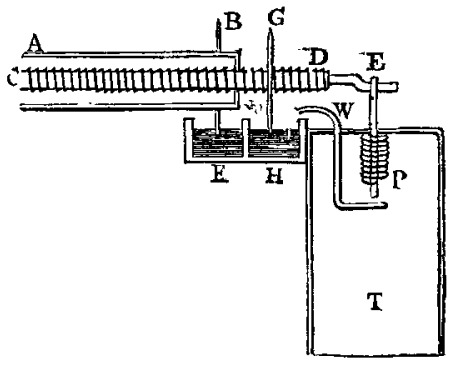

B and C. The revolving lifter of soft iron is considerably longer

* If $x_{2}$ denote the logarithm of 2 upon the scale in question, and $M$ the modulus of the common system, we shall have

Whence these numbers are computed.

$$
x_{\mathrm{Q}}=\frac{2 a}{\mathrm{M}} \log 2 .
$$

$\uparrow$ Communicated by the Author. 
Prof. Forbes on the Mathemalecal Form of the

Gothic Pendant

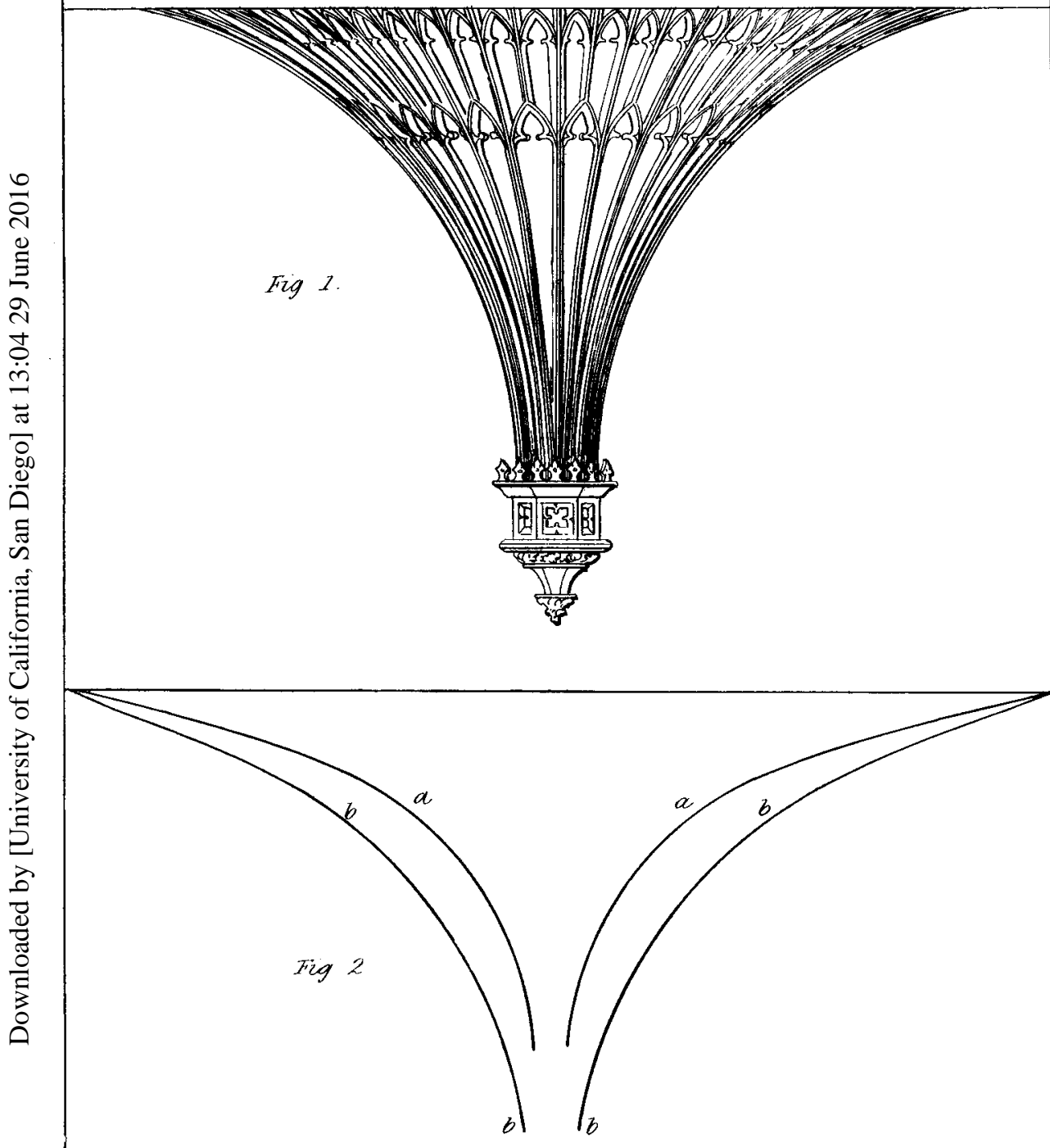

Pendants of uniform strength

of Marble (b) and Portand Stone (a) 